\title{
Identifikasi dan Analisis Risiko Keselamatan dan Kesehatan Kerja (K3) pada Proses Instalasi Hydraulic System Menggunakan Metode HIRA (Hazard Identification and Risk Assesment) di PT. HPP
}

\author{
Muhamad Bob Anthony \\ Teknik Industri Universitas Serang Raya \\ Jalan Raya Cilegon Km.5 Banten 42162, Indonesia \\ Email : tonipbmti@gmail.com
}

\section{Identification and Analysis of Occupational Health and Safety (OHS) Risks in the Hydraulic System Installation Process Using HIRA (Hazard Identification and Risk Assessment) Method at PT. HPP}

Dikirimkan: 08, 2020. Diterima: 09, 2020. Dipublikasikan: 09, 2020.

\begin{abstract}
This study aims to determine the risk value of potential occupational hazards and the level of potential risk of occupational hazards and to determine the potential occupational hazards that can cause occupational accidents at PT. HPP which is engaged in consulting services as well as implementation in the field of hydraulic of heavy equipment. This study uses an approach with the HIRA (Hazard Identification and Risk Assessment) method to calculate the values of risk before there is control (basic risk) until after controlling for the risk (existing risk). The results of research on the work process activities at the hydraulic system facilities in heavy equipment of PT. HPP found that 33 basic risks consisting of acceptable categories of 3 risks (9.09\%), priority 3 categories of 8 risks (24.24\%), substantial categories (priority 2) of 8 risks (24, $24 \%)$, priority 1 category was 5 risks (15.15\%) and very high category was 9 risks (27.27\%). After controlling for the existing risk, there is a reduction in risk, namely acceptable category as much as 3 risks (9.09\%), priority category as much as 8 risks (24.24\%), substantial category (priority 2) as much as 8 risks (24.24\%), priority 1 category 5 risks (15.15\%) and very high category 9 risks (27.27\%).
\end{abstract}

Keywords—basic risk, existing risk, HIRA.

\begin{abstract}
Abstrak - Penelitian ini memiliki tujuan untuk mengetahui nilai risiko potensi bahaya kerja dan level risiko potensi bahaya kerja serta mengetahui potensi bahaya kerja dominan yang dapat menyebabkan terjadinya kecelakaan kerja di PT. HPP yang bergerak di bidang jasa konsultasi maupun pelaksanaan di bidang peralatan hydraulic alat berat (heavy equipment). Penelitian ini menggunakan pendekatan dengan metode HIRA (Hazard Identification and Risk Assesment) untuk menghitung nilai-nilai risiko sebelum ada pengendalian (basic risk) sampai setelah dilakukan pengendalian terhadap risiko (existing risk). Hasil penelitian dari kegiatan proses kerja pada fasilitas system hydraulic di peralatan berat (heavy equipment) PT. HPP ini didapatkan 33 basic risk yang terdiri dari kategori dapat diterima (acceptable) sebanyak 3 risiko $(9,09 \%)$, kategori priority 3 sebanyak 8 risiko $(24,24 \%)$, kategori substantial (priority 2) sebanyak 8 risiko $(24,24 \%)$, kategori priority 1 sebanyak 5 risiko $(15,15 \%)$ dan kategori very high sebanyak 9 risiko $(27,27 \%)$. Setelah dilakukan pengendalian terhadap risiko (existing risk) didapatkan penurunan resiko yaitu kategori yang dapat diterima (acceptable) sebanyak 3 risiko $(9,09 \%)$, kategori priority 3 sebanyak 8 risiko $(24,24 \%)$, kategori substantial (priority 2) sebanyak 8 risiko $(24,24 \%)$, kategori priority 1 sebanyak 5 risiko $(15,15 \%)$ dan kategori very high sebanyak 9 risiko $(27,27 \%)$.
\end{abstract} Kata kunci-HIRA, risiko dasar, risiko yang ada. 


\section{PENDAHULUAN}

Manusia sebagai tenaga kerja selalu berhubungan dengan mesin, peralatan dan tempat kerja yang kemungkinan akan menimbulkan risiko kerja. Setiap tempat kerja selalu mempunyai risiko terjadinya kecelakaan. Besarnya risiko yang terjadi tergantung dari jenis industri, teknologi serta upaya pengendalian risiko yang dilakukan. Potensi bahaya banyak terdapat di tempat kerja dan mengakibatkan kerugian baik dari perusahaan, pekerja maupun terhadap masyarakat sekitar. Keselamatan dan Kesehatan Kerja (K3) merupakan sarana utama untuk pencegahan kecelakaan kerja, cacat dan kematian sehingga akibat kecelakaan kerja yang bersumber dari potensi bahaya yang ada dapat dicegah. Keselamatan dan kesehatan kerja (K3) adalah suatu kondisi kerja yang terbebas dari risiko kecelakaan yang dapat mengakibatkan cidera, penyakit, kerusakan serta gangguan lingkungan. Kondisi kerja tersebut merupakan hak dari setiap pekerja yang harus dipenuhi oleh setiap perusahaan. Salah satu tujuan K3 adalah untuk mencapai zero accident [1].

Pada umumnya kecelakaan kerja dapat di sebabkan oleh dua faktor yaitu manusia dan lingkungan. Faktor manusia yaitu kekurang hatihatian serta tindakan dari manusia yang tidak di sengaja melanggar peraturan keselamatan kerja sedangkan faktor lingkungan adalah tindakan yang tidak aman dari lingkungan kerja antara lain meliputi mesin-mesin dan peralatan kerja [2].

Sasaran utama program K3 adalah mengelola risiko untuk mencegah terjadinya kecelakaan atau kejadian yang tidak diinginkan melalui proses identifikasi bahaya, penilaian risiko dan pengendaliannya. Identifikasi bahaya dapat mengurangi peluang terjadinya kecelakaan karena identifikasi bahaya berkaitan dengan faktor penyebab kecelakaan [3]. Dengan melakukan identifikasi bahaya maka sumber-sumber bahaya dapat diketahui sehingga kemungkinan kecelakaan dapat ditekan [1].

Hazard Identification and Risk Assessment (HIRA) merupakan salah satu metode identifikasi kecelakaan kerja dengan penilaian risiko sebagai salah satu poin penting untuk mengimplementasikan Sistem Manajemen Keselamatan dan Kesehatan Kerja (SMK3) [4].

Hazard Identification and Risk Assessment (HIRA) merupakan salah satu metode untuk memudahkan identifikasi bahaya, melakukan penilaian risiko serta memberikan upaya pengendalian sesuai dengan tingkat risiko untuk menurunkan potensi bahaya [5].
PT. HPP adalah sebuah perusahaan nasional yang bergerak di bidang jasa konsultasi maupun pelaksanaan di bidang peralatan hydraulic system alat berat (heavy equipment). PT. HPP mengalami banyak kecelakaan kerja pada kuartal pertama tahun berjalan dan ini menyebabkan kerugian secara langsung maupun tidak langsung bagi perusahaan. Secara langsung, perusahaan harus mengganti kerusakan yang ada dan juga memberikan biaya pengobatan serta perawatan. Sementara secara tidak langsung, perusahaan mengalami ketidakproduktifan yang diakibatkan karena pekerja yang mengalami kecelakaan kerja tidak dapat berkontribusi pada perusahaan. Lebih jauh lagi, kecelakaan kerja mengakibatkan kegiatan operasional berhenti karena alat, mesin dan pekerja yang mengalami gangguan (trouble).

TABEL I

KECELAKAAN KERJA DI PT. HPP

\begin{tabular}{|l|c|c|c|}
\hline \multirow{2}{*}{ Kasus } & \multicolumn{3}{|c|}{ Bulan } \\
\cline { 2 - 4 } & Januari & Februari & Maret \\
\hline Kematian & 0 & 0 & 0 \\
\hline Cacat & 0 & 0 & 0 \\
\hline $\begin{array}{l}\text { Kasus Hilang } \\
\text { Kerja }\end{array}$ & 2 & 4 & 3 \\
\hline $\begin{array}{l}\text { Kasus } \\
\text { Perawatan } \\
\text { Medis }\end{array}$ & 4 & 6 & 5 \\
\hline Kotak P3K & 8 & 7 & 8 \\
\hline $\begin{array}{l}\text { Api Atau } \\
\text { Ledakan }\end{array}$ & 0 & 0 & 0 \\
\hline $\begin{array}{l}\text { Polusi } \\
\text { Lingkungan }\end{array}$ & 0 & 0 & 0 \\
\hline $\begin{array}{l}\text { Hampir Terjadi } \\
\text { Kecelakaan }\end{array}$ & 6 & 4 & 7 \\
\hline $\begin{array}{l}\text { Kasus Hari } \\
\text { Kerja Terbatas }\end{array}$ & 0 & 0 & 0 \\
\hline \multicolumn{1}{c|}{ Jumlah } & 20 & 21 & 23 \\
\hline
\end{tabular}

Dengan masih banyaknya kasus-kasus kecelakaan kerja yang terjadi, maka sangatlah diperlukan suatu penelitian yang dapat mengidentifikasi dan menganalisa bahaya ditempat kerja para pekerja. Dengan mengidentifikasi dan menganalisa potensi bahaya tersebut, pihak perusahaan dapat melakukan usaha mitigasi terhadap potensi bahaya yang mungkin terjadi dan pemerintah sebagai regulator dapat melakukan pengawasan dan penekanan terhadap penerapan peraturan kesehatan dan keselamatan pekerja.

Hasil kajian riset ini dapat menjadi benchmarking studi keselamatan dan kesehatan kerja (K3) di Indonesia dan dapat menjadi rekomendasi bagi pihak manajemen internal PT. HPP dan pemerintah sehingga dapat membantu meningkatkan kesejahteraan para pekerja dalam 
melakukan kegiatan pekerjaan dalam ruang lingkupnya masing-masing.

\section{METOdologi Penelitian}

Penelitian ini dilakukan di PT. HPP yang bergerak dibidang jasa konsultasi maupun pelaksanaan di bidang peralatan hydraulic system alat berat (heavy equipment). Objek yang diteliti adalah bahaya dan risiko yang terdapat dalam proses kerja pada fasilitas hydraulic system di peralatan berat (heavy equipment) PT. HPP dan data yang diambil adalah data laporan perusahaan pada fasilitas hydraulic system tersebut.

Pengolahan data dalam penelitian ini menggunakan metode Hazard Identifications and Risk Assessment (HIRA) yang terdiri dari mengidentifikasi bahaya dan penilaian tingkat risiko dengan menghitung nilai risk level. Data yang diperoleh dalam penelitian ini bersumber dari data primer maupun sekunder. Data primer diperoleh melalui observasi lapangan, wawancara serta melakukan diskusi dengan karyawan di PT. HPP pada fasilitas hydraulic system untuk mendapatkan hasil mengenai kemungkinan dan dampak risiko keselamatan dan kesehatan kerja (K3). Data sekunder di diperoleh dari dokumendokumen serta catatan-catatan perusahaan yang berhubungan dengan masalah yang diteliti dan keselamatan dan kesehatan kerja (K3) serta dari sumber atau data lain sebagai pelengkap penelitian ini.

Pengolahan data dilakukan dengan menggunakan metode Hazard Identification and Risk Assessment (HIRA) dan matriks risiko yang telah ditetapkan. Proses identifikasi menggunakan HIRA adalah identifikasi bahaya, analisa risiko dan menetapkan tindakan pengendalian.

Risk $=\underset{(\text { probability) }}{\mathrm{C} \text { (consequence) }} \mathrm{x} \mathrm{E}$ (exposure) $\mathrm{x} \underset{(1)}{\mathrm{P}}$

Keterangan :

Risk adalah risiko

$\mathrm{C}$ (consequence) adalah akibat yang mungkin ditimbulkan dari suatu peristiwa

E (exposure) adalah frekuensi pemaparan terhadap bahaya atau sumber resiko

$\mathrm{P}$ (probability) adalah kemungkinan terjadinya bahaya.

TABEL II

CONSEQUENCE

\begin{tabular}{|c|c|c|c|}
\hline Faktor & Tingkatan & Deskripsi & Rating \\
\hline $\begin{array}{l}\text { Consequence } \\
\text { (akibat yang }\end{array}$ & Catastrophe & $\begin{array}{l}\text { Kerusakan } \\
\text { fatal/parah }\end{array}$ & 100 \\
\hline
\end{tabular}

\begin{tabular}{|c|c|c|c|}
\hline \multirow[t]{5}{*}{$\begin{array}{l}\text { mungkin } \\
\text { ditimbulkan } \\
\text { dari suatu } \\
\text { peristiwa) }\end{array}$} & & $\begin{array}{l}\text { beragam } \\
\text { fasilitas, } \\
\text { kerugian } \\
\text { lebih dari } \\
\$ 1 \text { juta, } \\
\text { aktivitas } \\
\text { dihentikan, } \\
\text { terjadi } \\
\text { kerusakan } \\
\text { lingkungan } \\
\text { yang sangat } \\
\text { luas }\end{array}$ & \\
\hline & Disaster & $\begin{array}{l}\text { Bersifat } \\
\text { lokal } \\
\text { terhadap } \\
\text { lingkungan, } \\
\text { kerugian } \\
\$ 500.000- \\
2.000 .000\end{array}$ & 50 \\
\hline & Very Serious & $\begin{array}{l}\text { Terjadi } \\
\text { cacat } \\
\text { permanen/ } \\
\text { penyakit } \\
\text { parah } \\
\text { hingga } \\
\text { kematian, } \\
\text { kerusakan } \\
\text { lingkungan } \\
\text { yang tidak } \\
\text { permanen, } \\
\text { dengan } \\
\text { kerugian } \\
\$ 50 . \quad 000- \\
500.000\end{array}$ & 25 \\
\hline & Serious & $\begin{array}{l}\text { Terjadi } \\
\text { dampak } \\
\text { yang serius, } \\
\text { cidera dan } \\
\text { menimbulk } \\
\text { an penyakit } \\
\text { yang } \\
\text { permanen, } \\
\text { sedikit } \\
\text { berakibat } \\
\text { buruk pada } \\
\text { ligkungan, } \\
\text { dengan } \\
\text { kerugian } \\
\$ 5 \text {. 000- } \\
50.000\end{array}$ & 15 \\
\hline & Important & $\begin{array}{l}\text { Membutuh } \\
\text { kan } \\
\text { penanganan } \\
\text { medis, } \\
\text { terjadi } \\
\text { emisi } \\
\text { buangan } \\
\text { dilokasi }\end{array}$ & 5 \\
\hline
\end{tabular}


Jurnal Media

Teknik dan

Sistem Industri

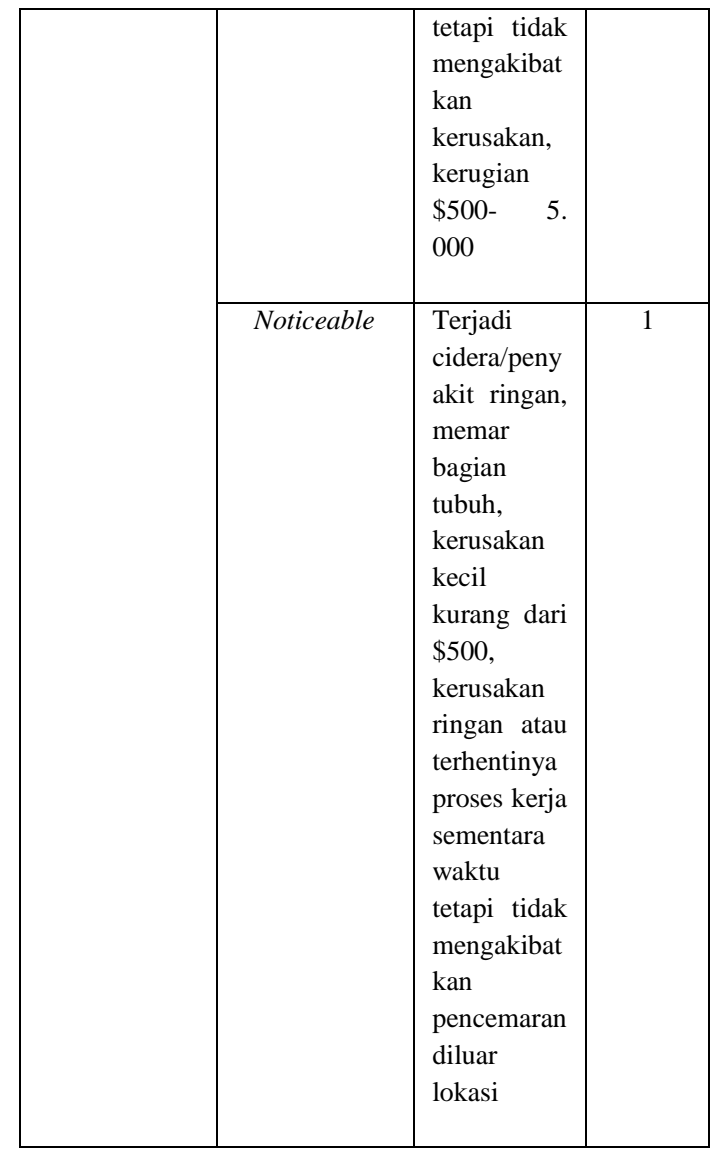

TABEL III

EXPOSURE

\begin{tabular}{|l|l|l|c|}
\hline Faktor & Tingkatan & Deskripsi & Rating \\
\hline $\begin{array}{l}\text { Exposure } \\
\text { atau } \\
\text { paparan } \\
\text { (frekuensi } \\
\text { pemaparan } \\
\text { terhadap } \\
\text { bahaya } \\
\text { atau } \\
\text { sumber } \\
\text { risiko) }\end{array}$ & Continously & $\begin{array}{l}\text { Sering terjadi } \\
\text { dalam satu hari }\end{array}$ & 10 \\
\cline { 2 - 4 } & Frequently & $\begin{array}{l}\text { Terjadi kira- } \\
\text { kira satu kali } \\
\text { dalam sehari }\end{array}$ & 6 \\
\cline { 2 - 4 } & Onfrequent & $\begin{array}{l}\text { Terjadi satu } \\
\text { kali seminggu } \\
\text { sampai satu } \\
\text { kali sebulan }\end{array}$ & 3 \\
\cline { 2 - 4 } & $\begin{array}{l}\text { Terjadi satu } \\
\text { kali sebulan } \\
\text { sampai satu } \\
\text { kali setahun }\end{array}$ & 2 \\
\cline { 2 - 4 } & Rare & $\begin{array}{l}\text { Diketahui } \\
\text { kapan } \\
\text { terjadinya }\end{array}$ & 1 \\
\cline { 2 - 4 } & Very Rare & $\begin{array}{l}\text { Tidak } \\
\text { diketahui } \\
\text { kapan }\end{array}$ & 0.5 \\
\hline \multirow{2}{*}{} & & & \\
\hline
\end{tabular}

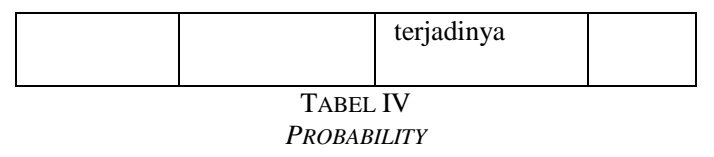

\begin{tabular}{|c|c|c|c|}
\hline Faktor & Tingkatan & Deskripsi & Rating \\
\hline \multirow{6}{*}{$\begin{array}{l}\text { Probability } \\
\text { (kemampua } \\
\text { n terjadinya } \\
\text { bahaya } \\
\text { menyertai } \\
\text { suatu } \\
\text { kejadian } \\
\text { atau } \\
\text { peristiwa ) }\end{array}$} & $\begin{array}{l}\text { Almost } \\
\text { Certain }\end{array}$ & $\begin{array}{l}\text { Kejadian yang } \\
\text { paling sering } \\
\text { teriadi }\end{array}$ & 10 \\
\hline & Likely & $\begin{array}{l}\text { Kemungkinan } \\
\text { kecelakaan 50\% }\end{array}$ & 6 \\
\hline & $\begin{array}{l}\text { Unusual but } \\
\text { possible }\end{array}$ & $\begin{array}{l}\text { Tidak biasa, } \\
\text { namun } \\
\text { kemungkinan } \\
\text { dapat terjadi }\end{array}$ & 3 \\
\hline & $\begin{array}{l}\text { Remotely } \\
\text { possible }\end{array}$ & $\begin{array}{l}\text { Suatu kejadian } \\
\text { yang sangat kecil } \\
\text { kemungkinan } \\
\text { terjadinya }\end{array}$ & 1 \\
\hline & Concievable & $\begin{array}{l}\text { Tidak pernah } \\
\text { terjadi kecelakaan } \\
\text { dalam tahun-tahun } \\
\text { pemaparan tapi } \\
\text { mungkin terjadi }\end{array}$ & 0.5 \\
\hline & $\begin{array}{l}\text { Pratically } \\
\text { imposible }\end{array}$ & $\begin{array}{l}\text { Sangat mungkin } \\
\text { tidak terjadi }\end{array}$ & 0.1 \\
\hline
\end{tabular}

Selanjutnya untuk melihat tingkat risiko (risk level) setelah melakukan perhitungan risk dapat menggunakan pada tabel dibawah ini :

TABEL V

LEVEL RISIKO

\begin{tabular}{|l|l|l|}
\hline $\begin{array}{l}\text { Tingkat } \\
\text { resiko }\end{array}$ & Comment & \multicolumn{1}{|c|}{ Action } \\
\hline$>350$ & Very High & $\begin{array}{l}\text { Penghentian aktivitas, risiko } \\
\text { dikurangi hingga batas yang bisa } \\
\text { diterima }\end{array}$ \\
\hline $180-350$ & Priority 1 & Perlu penanganan secepatnya \\
\hline $70-180$ & $\begin{array}{l}\text { Substansial } \\
\text { priority 2) }\end{array}$ & $\begin{array}{l}\text { Mengharuskan ada perbaikan } \\
\text { secara teknis }\end{array}$ \\
\hline $20-70$ & Priority 3 & $\begin{array}{l}\text { Perlu diawasi dan diperhatikan } \\
\text { secara berkesinambungan }\end{array}$ \\
\hline$<20$ & Acceptable & $\begin{array}{l}\text { Insensitas kegiatan yang } \\
\text { menimbulkan risiko dikurangi } \\
\text { seminimal mungkin }\end{array}$ \\
\hline
\end{tabular}


Setelah melakukan penghitungan tingkat risiko dengan menghitung nilai risiko, tahapan selanjutnya melakukan analisis tingkat risiko dengan melakukan pengelompokan dan membuat mitigasi atau pengendalian tambahan (additional control) untuk mencegah atau meminimalisasi kecelakaan kerja pada instalasi hydraulic system.

Risk reduction $=($ basic level $\mathrm{x}$ existing level $\mathrm{x}$ $100 \%)$ : basic level

\section{HASIL PENELITIAN}

Penilaian risiko dibuat dengan mengalikan faktor dampak (consequence), paparan (exposure) dan kemungkinan (probability) risiko semua proses kerja pada fasilitas hydraulic system di peralatan berat (heavy equipment) PT. HPP.

Nilai basic risk menggambarkan risiko dasar yang ada di tempat kerja sedangkan nilai existing risk menggambarkan tingkat risiko yang ada dengan pertimbangan tindakan pengendalian telah dilakukan. Di bawah ini merupakan data-data potensi bahaya (hazard) proses kerja pada fasilitas hydraulic system di peralatan berat (heavy equipment) PT. HPP yang didapat dari hasil penelitian dan wawancara dengan pekerja perusahaan.

TABEL VI

IDENTIFIKASI BAHAYA

\begin{tabular}{|c|c|c|}
\hline No & Urutan Aktivitas & Hazard \\
\hline 1 & $\begin{array}{c}\text { Pekerja mengukur } \\
\text { panjang hose } \\
\text { hydraulic yang } \\
\text { akan digunakan } \\
\text { menggunakan } \\
\text { meteran }\end{array}$ & $\begin{array}{c}\text { hazard mekanik : tergores } \\
\text { meteran }\end{array}$ \\
\hline 2 & $\begin{array}{l}\text { Memotong hose } \\
\text { hydraulic sesuai } \\
\text { panjang / ukuran } \\
\text { yang akan } \\
\text { digunakan, } \\
\text { menggunakan } \\
\text { gerinda }\end{array}$ & $\begin{array}{l}\text { hazard mekanik: terkena mata } \\
\text { gerinda } \\
\text { hazard fisik : terpapar bising } \\
\text { hazard fisik : terpapar getaran } \\
\text { hazard mekanik : terkena } \\
\text { percikan api } \\
\text { hazard fisik : mata terkena } \\
\text { serpihan hose } \\
\text { hazard fisik : terpapar asap } \\
\text { pemotongan hose }\end{array}$ \\
\hline 3 & $\begin{array}{l}\text { Penyerutan ujung } \\
\text { hose hydraulic } \\
\text { masih } \\
\text { menggunakan } \\
\text { sillet cutter } \\
\end{array}$ & $\begin{array}{l}\text { hazard fisik : tangan terkena } \\
\text { sillet cutter } \\
\text { hazard mekanik : sillet cutter } \\
\text { patah mengenai kaki }\end{array}$ \\
\hline 4 & $\begin{array}{c}\text { Penghalusan } \\
\text { ujung konektor } \\
\text { baru }\end{array}$ & $\begin{array}{c}\text { hazard mekanik : terkena } \\
\text { mata gerinda } \\
\text { hazard fisik : terpapar bising } \\
\text { hazard fisik : terpapar } \\
\text { getaran } \\
\text { hazard fisik : mata terkena } \\
\text { serpihan besi }\end{array}$ \\
\hline
\end{tabular}

\begin{tabular}{|c|c|c|}
\hline 5 & $\begin{array}{l}\text { Pembongkaran } \\
\text { konektor bekas }\end{array}$ & $\begin{array}{l}\text { hazard fisik : terkena mata } \\
\text { gerinda } \\
\text { hazard fisik : terpapar bising } \\
\text { hazard fisik : terpapar } \\
\text { getaran } \\
\text { hazard fisik : terkena } \\
\text { percikan api } \\
\text { hazard fisik : mata terkena } \\
\text { serpihan } \\
\text { hazard fisik : tangan terpalu } \\
\text { hazard fisik : kaki terpahat }\end{array}$ \\
\hline 6 & $\begin{array}{l}\text { Penekanan } \\
\text { (press) klem } \\
\text { dan konektor } \\
\text { pada hose } \\
\text { hydraulic }\end{array}$ & $\begin{array}{c}\text { hazard fisik: tangan } \\
\text { tertusuk kawat } \\
\text { hazard mekanik : selang } \\
\text { mesin press pecah }\end{array}$ \\
\hline 7 & $\begin{array}{c}\text { Pemasangan } \\
\text { spring atau } \\
\text { pelindung hose } \\
\text { hydraulic }\end{array}$ & hazard fisik : tangan terjepit \\
\hline 8 & Menaiki tangga & $\begin{array}{l}\text { hazard mekanik : terjatuh dari } \\
\text { tangga }\end{array}$ \\
\hline 9 & $\begin{array}{l}\text { Mengendurkan } \\
\text { dan memasang } \\
\text { hose hydraulic } \\
\text { dari heavy } \\
\text { equipment } \\
\text { (excavator) }\end{array}$ & $\begin{array}{c}\text { hazard mekanik : oli } \\
\text { mengenai wajah } \\
\text { hazard fisik : kaki tertimpa } \\
\text { kunci }\end{array}$ \\
\hline 10 & $\begin{array}{l}\text { Melepas hose } \\
\text { hydraulic dari } \\
\text { heavy equipment } \\
\text { (excavator) }\end{array}$ & $\begin{array}{c}\text { hazard fisik : hose menimpa } \\
\text { pekerja lain }\end{array}$ \\
\hline 11 & $\begin{array}{c}\text { Melepas hose } \\
\text { hydraulic dari } \\
\text { heavy equipment } \\
\text { (dump truck) }\end{array}$ & $\begin{array}{c}\text { hazard mekanik : tertimpa bak } \\
\text { dump truck }\end{array}$ \\
\hline 12 & $\begin{array}{c}\text { Melepas dan } \\
\text { memasang } \\
\text { hose hydraulic } \\
\text { pada heavy } \\
\text { equipment } \\
\text { (loader) }\end{array}$ & $\begin{array}{l}\text { hazard fisik : kepala } \\
\text { terbentur body loader } \\
\text { hazard fisik : tangan terkena } \\
\text { mesin panas }\end{array}$ \\
\hline 13 & $\begin{array}{l}\text { Mengangkat hose } \\
\text { hydraulic baru ke } \\
\text { atas menggunakan } \\
\text { tangga }\end{array}$ & $\begin{array}{l}\text { hazard ergonomi : manual } \\
\text { lifting } \\
\text { hazard mekanik : terjatuh } \\
\text { dari tangga }\end{array}$ \\
\hline 14 & $\begin{array}{l}\text { Pelepasan dan } \\
\text { pemasangan hose } \\
\text { hydraulic pada } \\
\text { heavy equipment } \\
\text { (crane) standby. }\end{array}$ & hazard fisik : pekerja terjatuh \\
\hline 15 & $\begin{array}{l}\text { Mengangkat hose } \\
\text { hydraulic baru ke } \\
\text { atas crane. }\end{array}$ & $\begin{array}{l}\text { hazard ergonomi : manual } \\
\text { lifting } \\
\text { hazard mekanik : hose } \\
\text { menimpa pekerja }\end{array}$ \\
\hline
\end{tabular}


Jurnal Media

Teknik dan

Sistem Industri

TABEL VII

ANALISA RISIKO BASIC RISK

\begin{tabular}{|c|c|c|c|c|c|c|}
\hline No & Risiko & $\mathbf{C}$ & $\mathbf{E}$ & $\mathbf{P}$ & $\begin{array}{c}\text { Basic } \\
\text { risk }\end{array}$ & Risk level \\
\hline 1 & \begin{tabular}{|l} 
Tergores \\
meteran
\end{tabular} & 1 & 10 & 6 & 60 & priority 3 \\
\hline 2 & $\begin{array}{l}\text { Terkena } \\
\text { mata } \\
\text { gerinda }\end{array}$ & 5 & 10 & 6 & 300 & priority 1 \\
\hline & $\begin{array}{l}\text { Terpapar } \\
\text { bising }\end{array}$ & 15 & 10 & 3 & 450 & very high \\
\hline & $\begin{array}{l}\text { Terpapar } \\
\text { getaran }\end{array}$ & 15 & 10 & 3 & 450 & very high \\
\hline & $\begin{array}{l}\text { Terkena } \\
\text { percikan } \\
\text { api }\end{array}$ & 1 & 10 & 6 & 60 & priority 3 \\
\hline & \begin{tabular}{|l|} 
Terpapar \\
asap \\
pemotong \\
an hose \\
hydraulic \\
\end{tabular} & 15 & 10 & 1 & 150 & substantial \\
\hline & $\begin{array}{l}\text { Mata } \\
\text { terkena } \\
\text { serpihan } \\
\text { besi }\end{array}$ & 25 & 10 & 3 & 750 & very high \\
\hline 3 & $\begin{array}{l}\text { Tangan } \\
\text { terkena } \\
\text { sillet } \\
\text { cutter }\end{array}$ & 1 & 10 & 6 & 60 & priority 3 \\
\hline & \begin{tabular}{|l|} 
Sillet \\
cutter \\
patah \\
mengenai \\
kaki
\end{tabular} & 1 & 10 & 1 & 10 & acceptable \\
\hline 4 & \begin{tabular}{|l|} 
Terkena \\
mata \\
gerinda
\end{tabular} & 5 & 10 & 6 & 300 & priority 1 \\
\hline & $\begin{array}{l}\text { Mata } \\
\text { terkena } \\
\text { serpihan } \\
\text { besi }\end{array}$ & 25 & 10 & 3 & 750 & very high \\
\hline 5 & $\begin{array}{l}\text { Terkena } \\
\text { mata } \\
\text { gerinda }\end{array}$ & 5 & 10 & 6 & 300 & priority 1 \\
\hline & $\begin{array}{l}\text { Terpapar } \\
\text { bising }\end{array}$ & 15 & 10 & 3 & 450 & very high \\
\hline & $\begin{array}{l}\text { Terpapar } \\
\text { getaran }\end{array}$ & 15 & 10 & 3 & 450 & very high \\
\hline & $\begin{array}{l}\text { Terkena } \\
\text { percikan } \\
\text { api }\end{array}$ & 1 & 10 & 6 & 60 & priority 3 \\
\hline & $\begin{array}{l}\text { Mata } \\
\text { terkena } \\
\text { serpihan } \\
\text { besi } \\
\end{array}$ & 25 & 10 & 3 & 750 & very high \\
\hline & $\begin{array}{l}\text { Tangan } \\
\text { terpalu }\end{array}$ & 1 & 10 & 10 & 100 & substansial \\
\hline & $\begin{array}{l}\text { Kaki } \\
\text { terpahat }\end{array}$ & 1 & 10 & 10 & 100 & substansial \\
\hline 6 & \begin{tabular}{|l} 
Tangan \\
tertusuk \\
kawat
\end{tabular} & 1 & 10 & 6 & 60 & priority 3 \\
\hline & $\begin{array}{l}\text { Selang } \\
\text { mesin } \\
\text { press } \\
\text { pecah }\end{array}$ & 15 & 10 & 3 & 450 & very high \\
\hline
\end{tabular}

\begin{tabular}{|c|l|c|c|c|c|c|}
\hline 7 & $\begin{array}{l}\text { Tangan } \\
\text { terjepit }\end{array}$ & 1 & 10 & 10 & 100 & substansial \\
\hline 8 & $\begin{array}{l}\text { Pekerja } \\
\text { terjatuh } \\
\text { dari } \\
\text { tangga }\end{array}$ & 15 & 2 & 6 & 180 & substansial \\
\hline 9 & $\begin{array}{l}\text { Oli } \\
\text { mengenai } \\
\text { wajah }\end{array}$ & 25 & 2 & 6 & 300 & priority 1 \\
\hline & $\begin{array}{l}\text { Kaki } \\
\text { tertimpa } \\
\text { kunci }\end{array}$ & 1 & 2 & 6 & 12 & acceptable \\
\hline 10 & $\begin{array}{l}\text { Hose } \\
\text { menimpa } \\
\text { pekerja } \\
\text { lain }\end{array}$ & 5 & 2 & 10 & 100 & substansial \\
\hline 11 & $\begin{array}{l}\text { Manual } \\
\text { lifting }\end{array}$ & 1 & 2 & 6 & 12 & acceptable \\
\hline & $\begin{array}{l}\text { Pekerja } \\
\text { terjatuh } \\
\text { dari } \\
\text { tangga }\end{array}$ & 5 & 2 & 6 & 60 & priority 3 \\
\hline 12 & $\begin{array}{l}\text { Tertimpa } \\
\text { bak dump } \\
\text { truck }\end{array}$ & 100 & 2 & 3 & 600 & very high \\
\hline 13 & $\begin{array}{l}\text { Terbentur } \\
\text { body } \\
\text { loader }\end{array}$ & 5 & 2 & 10 & 100 & substansial \\
\hline $\begin{array}{l}\text { Tangan } \\
\text { tarkena } \\
\text { mesin } \\
\text { panas }\end{array}$ & 1 & 2 & 10 & 20 & priority 3 \\
\hline 14 & $\begin{array}{l}\text { Pekerja } \\
\text { terjatuh }\end{array}$ & 25 & 2 & 6 & 300 & priority 1 \\
\hline 15 & $\begin{array}{l}\text { Manual } \\
\text { lifting }\end{array}$ & 1 & 2 & 10 & 20 & priority 3 \\
\hline & $\begin{array}{l}\text { Hose } \\
\text { menimpa } \\
\text { pekerja }\end{array}$ & 5 & 2 & 10 & 100 & substansial \\
\hline
\end{tabular}

Berdasarkan tabel di atas, didapatkan bahwa risiko proses kerja pada fasilitas hydraulic system di peralatan berat (heavy equipment) PT. HPP masih cukup tinggi. Oleh karena itu, PT. HPP harus melakukan mitigasi risiko agar proses kerja pada fasilitas hydraulic system di peralatan berat (heavy equipment) dalam kondisi aman dan dapat diterima (acceptable).

Berikut ini mitigasi atau pengendalian tambahan (additional control) yang diberikan agar proses kerja pada fasilitas hydraulic system di peralatan berat (heavy equipment) dalam kondisi aman dan dapat diterima (acceptable).

1. tergores meteran

a) JSA (job safety analysis), LMRA (last minute risk assesment) dan tool box meeting sebelum pekerjaan dimulai.

b) PPE (personal protection equipment) harus digunakan selama pekerjaan dilakukan sesuai PPE matrix.

2. terkena mata gerinda

a) pemasangan pelindung (cover) gerinda selama pekerjaan dilakukan. 
b) JSA (job safety analysis), LMRA (last minute risk assesment) dan tool box meeting sebelum pekerjaan dimulai.

c) PPE (personal protection equipment) harus digunakan selama pekerjaan dilakukan sesuai PPE matrix.

3. terpapar bising

a) Pemeriksaan kebisingan secara berkala dan melakukan proteksi area dari kebisingan.

b) Penggunaan ear plug atau earmuff selama pekerjaan berlangsung untuk mengurangi kebisingan.

4. terpapar getaran

a) melakukan pembatasan dalam jam kerja atau dilakukan secara bergantian.

b) PPE (personal protection equipment) harus digunakan selama pekerjaan dilakukan sesuai PPE matrix.

5. terkena percikan api

a) PPE (personal protection equipment) harus digunakan selama pekerjaan dilakukan sesuai PPE matrix.

b) memasang fire blanket.

c) menggunakan pakaian coverall (lengan dan celana panjang).

6. terpapar asap pemotongan hose

a) pekerjaan dilakukan di area terbuka atau membuat kubikal yang dilengkapi blower.

b) menggunakan half masker respirator selama pekerjaan.

7. mata terkena serpihan hose

a) pemasangan pelindung (cover) gerinda selama pekerjaan dilakukan.

b) PPE (personal protection equipment) harus digunakan selama pekerjaan dilakukan sesuai PPE matrix.

c) mengatur posisi agar berlawanan dengan arah angin.

8. tangan terkena sillet cutter

a) pemasangan pelindung (cover) selama pekerjaan dilakukan.

b) PPE (personal protection equipment) harus digunakan selama pekerjaan dilakukan sesuai PPE matrix.

c) pekerjaan harus dilakukan oleh orang yang kompeten

9. sillet cutter mengenai kaki

a) mengatur jarak aman dan posisi saat pekerjaan.

b) PPE (personal protection equipment) harus digunakan selama pekerjaan dilakukan sesuai PPE matrix.

10. tangan terpalu

a) gunakan palu nonspark.

b) mengatur jarak aman dan posisi saat pekerjaan.

11. kaki terpahat a) pemasangan pelindung (cover) selama pekerjaan dilakukan.

b) mengatur jarak aman pekerjaan dan memakai PPE (personal protection equipment) sesuai PPE matrix.

12. tangan tertusuk kawat

a) mengatur jarak aman pekerjaan dan memakai PPE (personal protection equipment) sesuai PPE matrix.

13. selang mesin press pecah

a) melapisi selang mesin press dengan spring (pelindung hose).

b) melakukan pengecekan peralatan sebelum digunakan.

14. tangan terjepit

a) koordinasi antara pekerja selama pekerjaan.

b) PPE (personal protection equipment) harus digunakan selama pekerjaan dilakukan sesuai PPE matrix.

15. pekerja terjatuh dari tangga

a) menggunakan three point contact selama pekerjaan dan safety body harness jika diperlukan.

b) melakukan pelatihan bekerja di atas ketinggian sebelum pekerjaan dimulai.

16. oli mengenai wajah

a) melakukan pengecekan sebelum pekerjaan dimulai dan memastikan bahwa area kerja aman.

b) PPE (personal protection equipment) harus digunakan selama pekerjaan dilakukan sesuai PPE matrix.

17. kaki tertimpa kunci

a) memastikan area aman sebelum bekerja dan mengatur jarak aman saat bekerja.

b) PPE (personal protection equipment) harus digunakan selama pekerjaan dilakukan sesuai PPE matrix.

18. hose menimpa pekerja lain

a) melakukan LMRA (last minute risk assesment) sebelum pekerjaan dimulai

b) memastikan area kerja aman dan melakukan koordinasi antara pekerja.

c) pengaturan pekerja dilapangan saat ada pekerjaan yang bersamaan (simultaneous operation).

19. manual lifting

a) pengangkatan disesuaikan dengan JSA

b) beban dan jumlah pekerja saat melakukan manual lifting harus sesuai dengan peraturan perundangan.

20. tertimpa bak dump truck

a) memastikan area kerja aman dan melakukan koordinasi antara pekerja

b) membuat double penopang besi.

c) melakukan isolasi area kerja. 
Jurnal Media

Teknik dan

Sistem Industri

21. terbentur body loader

a) memberikan warna yang mudah lihat selama pekerjaan dan memberikan tanda peringatan di depan peralatan tersebut.

22. tangan terkena mesin panas loader

a) melakukan isolasi area dan memberikan tanda petunjuk

b) mengatur jarak aman saat pekerjaan dilakukan.

23. pekerja terjatuh

a) melakukan pelatihan bekerja di atas ketinggian sebelum pekerjaan dimulai.

b) membuat emergency response plan dan drill (latihan tanggap darurat).

c) menggunakan full body harness untuk mencegah terjadinya pekerja terjatuh.

24. hose menimpa pekerja

a) melakukan LMRA (last minute risk assesment) sebelum pekerjaan dimulai

b) memastikan area aman sebelum bekerja dan melakukan isolasi terhadap area kerja.

c) PPE (personal protection equipment) sesuai dengan PPE matrix.

TABEL VIII

ANALISA RISIKO EXISTING RISK

\begin{tabular}{|c|c|c|c|c|c|c|}
\hline No & Risiko & C & $\mathbf{E}$ & $\mathbf{P}$ & $\begin{array}{c}\text { Existing } \\
\text { risk }\end{array}$ & Risk level \\
\hline 1 & $\begin{array}{l}\text { Tergores } \\
\text { meteran }\end{array}$ & 1 & 10 & 1 & 10 & Acceptable \\
\hline \multirow[t]{6}{*}{2} & $\begin{array}{l}\text { Terkena } \\
\text { mata gerinda }\end{array}$ & 5 & 10 & 1 & 50 & Priority 3 \\
\hline & $\begin{array}{l}\text { Terpapar } \\
\text { bising }\end{array}$ & 1 & 10 & 1 & 10 & Acceptable \\
\hline & $\begin{array}{l}\text { Terpapar } \\
\text { getaran }\end{array}$ & 1 & 10 & 1 & 10 & Acceptable \\
\hline & $\begin{array}{l}\text { Terkena } \\
\text { percikan api }\end{array}$ & 1 & 10 & 1 & 10 & Acceptable \\
\hline & \begin{tabular}{|l|} 
Terpapar \\
asap \\
pemotongan \\
hose \\
hydraulic \\
\end{tabular} & 1 & 10 & 0,5 & 5 & Acceptable \\
\hline & $\begin{array}{l}\text { Mata terkena } \\
\text { serpihan besi }\end{array}$ & 1 & 10 & 0,5 & 5 & Acceptable \\
\hline \multirow[t]{2}{*}{3} & \begin{tabular}{|l|} 
Tangan \\
terkena sillet \\
cutter
\end{tabular} & 1 & 10 & 1 & 10 & Acceptable \\
\hline & \begin{tabular}{|l|} 
Sillet cutter \\
patah \\
mengenai \\
kaki
\end{tabular} & 1 & 10 & 0,5 & 5 & Acceptable \\
\hline \multirow[t]{2}{*}{4} & $\begin{array}{l}\text { Terkena } \\
\text { mata gerinda }\end{array}$ & 5 & 10 & 1 & 50 & Priority 3 \\
\hline & $\begin{array}{l}\text { Mata terkena } \\
\text { serpihan besi }\end{array}$ & 1 & 10 & 0,5 & 5 & Acceptable \\
\hline \multirow[t]{2}{*}{5} & $\begin{array}{l}\text { Terkena } \\
\text { mata gerinda }\end{array}$ & 5 & 10 & 1 & 50 & Priority 3 \\
\hline & $\begin{array}{l}\text { Terpapar } \\
\text { bising }\end{array}$ & 1 & 10 & 1 & 10 & Acceptable \\
\hline
\end{tabular}

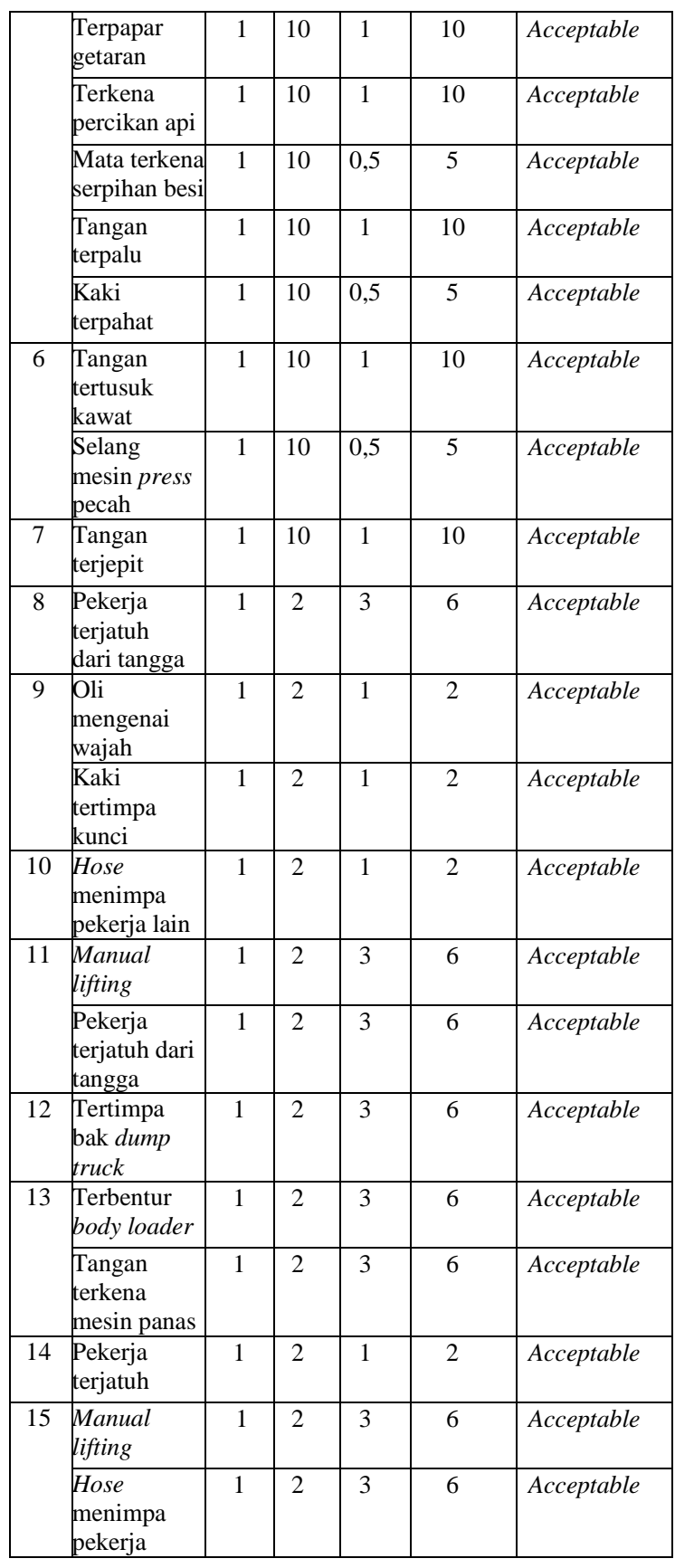

TABEL IX

RISK REDUCTION

\begin{tabular}{|c|l|c|c|}
\hline No & Risiko & Risk level & Risk reduction \\
\hline 1 & Tergores meteran & Acceptable & $83,33 \%$ \\
\hline 2 & Terkena mata gerinda & Priority 3 & $83,33 \%$ \\
\cline { 2 - 4 } & Terpapar bising & Acceptable & $97,78 \%$ \\
\cline { 2 - 4 } & Terpapar getaran & Acceptable & $97,78 \%$ \\
\cline { 2 - 4 } & Terkena percikan api & Acceptable & $83,33 \%$ \\
\hline
\end{tabular}




\begin{tabular}{|c|c|c|c|}
\hline & $\begin{array}{l}\text { Terpapar asap } \\
\text { pemotongan hose } \\
\text { hydraulic }\end{array}$ & Acceptable & $96,67 \%$ \\
\hline & $\begin{array}{l}\text { Mata terkena } \\
\text { serpihan besi }\end{array}$ & Acceptable & $90 \%$ \\
\hline 3 & $\begin{array}{l}\text { Tangan terkena sillet } \\
\text { cutter }\end{array}$ & Acceptable & $83,33 \%$ \\
\hline & $\begin{array}{l}\text { Sillet cutter patah } \\
\text { mengenai kaki }\end{array}$ & Acceptable & $50 \%$ \\
\hline 4 & Terkena mata gerinda & Priority 3 & $83,33 \%$ \\
\hline & $\begin{array}{l}\text { Mata terkena } \\
\text { serpihan besi }\end{array}$ & Acceptable & $90 \%$ \\
\hline 5 & Terkena mata gerinda & Priority 3 & $83,33 \%$ \\
\hline & Terpapar bising & Acceptable & $97,78 \%$ \\
\hline & Terpapar getaran & Acceptable & $97,78 \%$ \\
\hline & Terkena percikan api & Acceptable & $83,33 \%$ \\
\hline & $\begin{array}{l}\text { Mata terkena } \\
\text { serpihan besi }\end{array}$ & Acceptable & $90 \%$ \\
\hline & Tangan terpalu & Acceptable & $90 \%$ \\
\hline & Kaki terpahat & Acceptable & $98,33 \%$ \\
\hline \multirow[t]{2}{*}{6} & $\begin{array}{l}\text { Tangan tertusuk } \\
\text { kawat }\end{array}$ & Acceptable & $83,33 \%$ \\
\hline & $\begin{array}{l}\text { Selang mesin press } \\
\text { pecah }\end{array}$ & Acceptable & $98,89 \%$ \\
\hline 7 & Tangan terjepit & Acceptable & $90 \%$ \\
\hline 8 & $\begin{array}{l}\text { Pekerja terjatuh dari } \\
\text { tangga }\end{array}$ & Acceptable & $96,67 \%$ \\
\hline \multirow[t]{2}{*}{9} & Oli mengenai wajah & Acceptable & $93,33 \%$ \\
\hline & Kaki tertimpa kunci & Acceptable & $83,33 \%$ \\
\hline 10 & $\begin{array}{l}\text { Hose menimpa } \\
\text { pekerja lain }\end{array}$ & Acceptable & $96,67 \%$ \\
\hline \multirow[t]{2}{*}{11} & Manual lifting & Acceptable & $70 \%$ \\
\hline & $\begin{array}{l}\text { Pekerja terjatuh dari } \\
\text { tangga }\end{array}$ & Acceptable & $96,67 \%$ \\
\hline 12 & $\begin{array}{l}\text { Tertimpa bak dump } \\
\text { truck }\end{array}$ & Acceptable & $83,33 \%$ \\
\hline \multirow[t]{2}{*}{13} & $\begin{array}{l}\text { Terbentur body } \\
\text { loader }\end{array}$ & Acceptable & $50 \%$ \\
\hline & $\begin{array}{l}\text { Tangan terkena } \\
\text { mesin panas }\end{array}$ & Acceptable & $70 \%$ \\
\hline 14 & Pekerja terjatuh & Acceptable & $99,33 \%$ \\
\hline \multirow[t]{2}{*}{15} & Manual lifting & Acceptable & $70 \%$ \\
\hline & $\begin{array}{l}\text { Hose menimpa } \\
\text { pekerja }\end{array}$ & Acceptable & $80 \%$ \\
\hline
\end{tabular}

\section{PEMBAHASAN}

Dari hasil penelitian yang telah dilakukan, ditemukan 33 macam risiko sebagai hasil perhitungan dari risiko dasar yang ada (basic risk) sebagai berikut:

$$
\begin{aligned}
& \text { Acceptable }=\frac{3}{33} \times 100=9,09 \% \\
& \text { Priority } 3=\frac{8}{33} x 100=24,24 \% \\
& \text { Subtantial }=\frac{8}{33} \times 100=24,24 \% \\
& \text { Priority } 1=\frac{5}{33} \times 100=15,15 \% \\
& \text { Very high } \quad=\frac{9}{33} \times 100=27,27 \% \\
& \text { basic risk }
\end{aligned}
$$

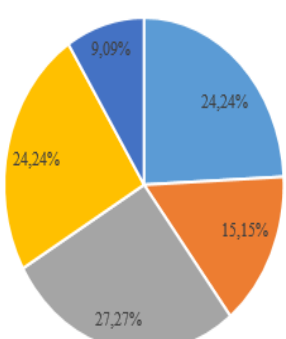

Hasil penilaian basic rick menunjukkan bahwa risiko yang berada pada kategori dapat diterima (acceptable) sebanyak 3 risiko $(9,09 \%)$, kategori priority 3 sebanyak 8 risiko (24,24\%), kategori substantial (priority 2) sebanyak 8 risiko $(24,24 \%)$, kategori priority 1 sebanyak 5 risiko $(15,15 \%)$ dan kategori very high sebanyak 9 risiko $(27,27 \%)$.

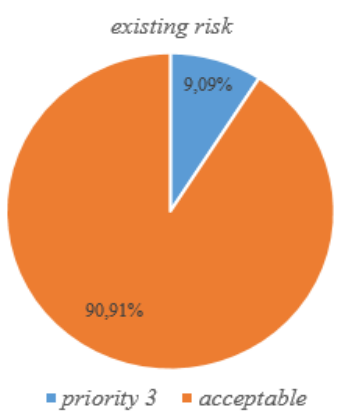

Gambar 2. Hasil penilaian existing risk

Dengan beberapa tindakan pengendalian yang dilakukan, maka dapat dihitung existing risk. Hasil dari perhitungan adalah sebagai berikut: 
Acceptable $=\frac{30}{33} \times 100 \%=90,91 \%$

Priority $3=\frac{3}{33} x 100=9,09 \%$

Berdasarkan Gambar 2 hasil dari penilaian existing risk, risiko yang berada pada kategori dapat di terima (acceptable) sebanyak 30 risiko $(90,91 \%)$ dan priority 3 sebanyak 3 risiko $(9,09 \%)$ sedangkan kategori priority 1 , substansial dan kategori very high risk telah hilang setelah dilakukan pengendalian atau mitigasi resiko.

Perbandingan dari basic risk dan existing risk dapat dilihat pada grafik berikut:

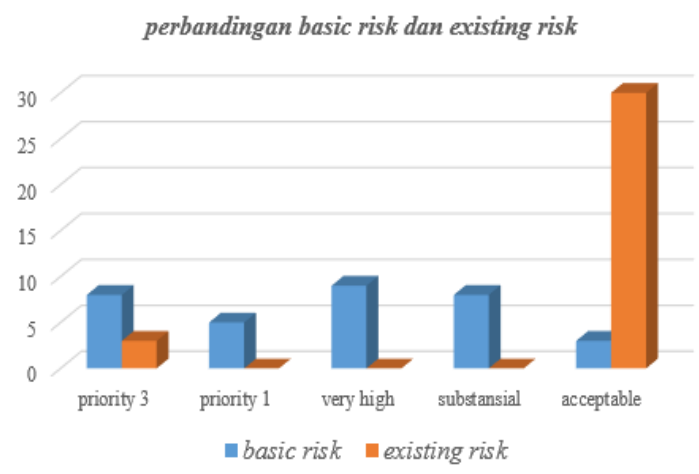

Gambar 3. Perbandingan basic risk dan existing risk

Pada Gambar 3 tersebut terlihat bahwa jumlah risiko yang dapat diterima (acceptable) pada existing risk lebih besar dari pada basic risk. Selanjutnya berturut-turut pada risiko kategori priority 3, very high, substantial (priority 2) dan Priority 1 mengalami penurunan. Ini menunjukkan bahwa semua risiko yang ada di proses kerja pada fasilitas hydraulic system di peralatan berat (heavy equipment) PT. HPP dinyatakan terkendali mengacu ke Tabel VIII dan Tabel IX di atas dan tindakan untuk melakukan pengendalian atau mitigasi risiko jauh lebih kecil dibandingkan dengan sebelumnya.

\section{KESIMPULAN}

Berdasarakan hasil penelitian yang telah dilakukan, maka dapat diambil kesimpulan sebagai berikut :

1. Dari hasil perhitungan sebelum adanya pengendalian risiko (basic rick), didapatkan bahwa risiko yang berada pada kategori yang dapat diterima (acceptable) sebanyak 3 risiko $(9,09 \%)$, kategori priority 3 sebanyak 8 risiko (24,24\%), kategori substantial (priority 2) sebanyak 8 risiko (24,24\%), kategori priority 1 sebanyak 5 risiko $(15,15 \%)$ dan kategori very high sebanyak 9 risiko $(27,27 \%)$.

2. Risiko terbesar (very high) sebelum dilakukan pengendalian risiko (basic risk) adalah pada proses memotong hose hydraulic sesuai panjang/ukuran yang akan digunakan, menggunakan gerinda, penghalusan ujung konektor baru, pembongkaran konektor bekas, penekanan (press) klem dan konektor pada hose hydraulic serta melepas dan memasang hose hydraulic pada heavy equipment (loader), .

3. Dari hasil perhitungan setelah dilakukan pengendalian atau mitigasi risiko (existing risk), didapatkan bahwa risiko yang berada pada kategori yang dapat di terima (acceptable) sebanyak 30 risiko $(90,91 \%)$ dan priority 3 sebanyak 3 risiko $(9,09 \%)$ sedangkan kategori priority 1, substansial dan kategori very high risk hilang setelah dilakukan pengendalian atau mitigasi resiko.

Hasil perhitungan jika dilakukan pengendalian atau mitigasi risiko (existing risk) menunjukkan bahwa semua risiko yang ada di proses kerja pada fasilitas hydraulic system di peralatan berat (heavy equipment) PT. HPP dinyatakan terkendali dan tindakan untuk melakukan pengendalian atau mitigasi resiko jauh lebih kecil dibandingkan dengan sebelumnya.

\section{REFERENSI}

[1] Ramli, S 2010. Sistem Manajemen Keselamatan dan Kesehatan Kerja OHSAS : 18001. Jakarta: Dian Rakyat.

[2] Sedarmayanti 2009. Sumber Daya Manusia dan Produktivitas Kerja Cetikan Ketiga. Bandung: CV.

[3] Restuputri, D. P., \& Sari, R. P. D. (2015). Analisis kecelakaan kerja dengan menggunakan metode Hazard and Operability Study (HAZOP). Jurnal Ilmiah Teknik Industri, 14(1), 24-35.

[4] Panjaitan, Nismah 2017. "Bahaya Kerja Pengolahan RSS (Ribbed Smoke Sheet) Menggunakan Metode Hazard Identification and Risk Assessment Di PT.PQR” Fakultas Teknik Industri Vol. 19 No. (02).

[5] Roehan, K. R. A, Yuniar \& Desrianty, A 2014. "Usulan Perbaikan Sistem Manajemen Keselamatan dan Kesehatan Kerja (SMK3) Menggunakan Metode Hazard Identification and Risk Assesment (HIRA)" Jurnal Online Institut Teknologi Nasional Vol. 02 No. (02).

[6] Ambarani, A. Y \& Tualeka A. R 2016. "Hazard Identification and Risk Assessment (HIRA) Pada proses fabrikasi Plate Tanki 42-T-501A PT. Pertamina (PERSERO) RU VI Balongan" Fakultas Kesehatan Masyarakat Universitas Airlangga Vol. 05 No. (02).

[7] Australian/New Zealand Standard. 2004. Australian Standard/New Zealand Standard 4360:2004 "Risk Mangement".

[8] Bird, E. Jr, Frank \& Germain, George L 1990 Practical Loss Control Leadership . Georgia.

[9] Cross, Jean 1998 Study notes: Risk Management, University of New south Wales, Sydney. 
[10] Daft, Marcic 2007 Manajemen: The New Workplace. Edisi Berilustrasi. Thomson South Western.

[11] Fuller, C.W, \& Vassie, L.H 2004 Health and safety management principles and best practice. England : Pearson Education Limited.

[12] Kolluru, V. Rao 1996. Risk Assesment and Management Handbook. New York, Mc Graw Hill.

[13] Prasetyo, E. H, Suroto, \& Kurniawan B 2018. “Analisis HIRA (Hazard Identification and Risk Assessment) Pada Instansi X Di Semarang" Fakultas Kesehatan Masyarakat Vol. 06 No. (05). 